\title{
A Sustentabilidade de Um Arranjo Produtivo Local no Polo Moveleiro de Arapongas
}

\section{The Sustainability of a Local Productive Arrangement In The Furniture Center of Arapongas}

\author{
Eliane Alves da Silva ${ }^{1}$, Paulo César Ribeiro Martins ${ }^{2}$ \\ ${ }^{1}$ Universidade Estadual de Londrina, UEL, Brasil \\ ${ }^{2}$ Cesupi Faculdade de Ilhéus, CESUPI, Brasil \\ Correspondência: Eliane Alves da Silva. Endereço: Av. Embaúbas, 2114, Centro CEP 78550212, Sinop, MT. \\ Tel.: 5566 3531-0355. E-mail: elianealvesil@yahoo.com.br
}

Recebido: 06 de junho de 2017 Aceito: 03 de setembro de 2016 Publicado: 01 de novembro de 2017

DOI: http://dx.doi.org/10.21714/1679-18272017v15n1.p86-98

\begin{abstract}
Resumo
O objetivo deste estudo foi analisar a sustentabilidade a longo prazo de um Arranjo Produtivo Local (APL) do Polo Moveleiro de Arapongas, no interior do Estado do Paraná, e as práticas da região por medidas socioambientais adequadas, por meio de um estudo de caso nas instituições que coordenam o projeto e por uma metodologia de análise da sustentabilidade, a qual combina as tradicionais metodologias de validação da competitividade com as metodologias de mensuração da sustentabilidade econômica e social. Foram entrevistados representantes da Organização da Sociedade Civil de Interesse Público (OSCIP) da usina de reciclagem de resíduos de madeira e do SENAI, chegando-se a um cenário que contempla a manutenção duradoura do APL para a competitividade das empresas do conglomerado industrial.
\end{abstract}

Palavras-chave: Administração; Arranjo Produtivo Local; Competitividade; Desenvolvimento; Sustentabilidade.

\begin{abstract}
This study aimed to analyze the sustainability of a Local Productive Arrangement (LPA) in the Furniture Center of Arapongas, in the State of Paraná. Through a case study in the institutions that coordinate the project and through a methodology of sustainability analysis, which combines the traditional methodologies of validation of competitiveness with the methodologies of measurement of economic and social sustainability. Representatives of Civil Society Organization for Public Interest (CSOP), the recycling plant of wood residues and SENAI were interviewed, reaching a scenario that contemplates the long-term maintenance of the LPA for the competitiveness of the companies in the industrial conglomerate.
\end{abstract}

Keywords: Administration; Local Productive Arrangement; Competitiveness; Development; Sustainability.

Esta obra está licenciada sob uma Licença Creative Commons Attribution 3.0

\section{Introdução}

A perspectiva adotada pelo World Business Council for Sustainable Develompment (WBCSD, 2011) acerca da responsabilidade social coorporativa é absorvida pelo mundo coorporativo, como o alcance do equilíbrio entre as três dimensões: a econômica, a ambiental e a social. As discussões sobre sustentabilidade e desenvolvimento sustentável levam a uma constatação do que antes era tido como uma responsabilidade central dos governos, passando a ser uma responsabilidade central das organizações, principalmente as privadas. Essa mudança torna propício o surgimento de Arranjos Produtivos Locais (APL) que fazem a manutenção da competitividade de empresas de determinada região.

O objetivo deste estudo foi analisar a sustentabilidade a longo prazo do APL do Polo Moveleiro de Arapongas e as práticas da região por medidas socioambientais adequadas. A indústria moveleira, juntamente com uma OSCIP, uma instituição de ensino e uma usina de reciclagem de iniciativa privada trabalham em conjunto para atender interesses particulares e regionais e a manutenção destes, que garantem a durabilidade do Arranjo 
Produtivo.

A relevância deste trabalho reside na análise do Polo Moveleiro de Arapongas esperando-se proporcionar melhores possibilidades de análise dos Arranjos Produtivos, orientando os definidores de políticas de apoio, fornecendo-lhes informações relevantes que servirão como parâmetro para implantação de novos APLs ou melhorias aos existentes. É importante que o Arranjo Produtivo seja considerado sustentável, não basta que o mesmo apenas se comporte de maneira sustentável, mas também que o local e a região onde ele se encontra inserido sejam considerados sustentáveis.

Sobre a metodologia, foram utilizadas as análises qualitativa e quantitativa. Conforme Minayo (2010), esses métodos de natureza diferenciada se complementam na compreensão da realidade social. Uma descrição extremamente precisa de todos os fatos conhecidos pode impedir qualquer representação matemática útil. Porém, uma simplificação do quadro matemático utilizado poderia ser totalmente inútil, porque muitos fatos relevantes teriam que ser omitidos.

Para análise qualitativa de caráter exploratório foi utilizado um estudo de caso. A escolha por esta abordagem ocorreu em função das diferenças dos contextos dos setores e das atividades econômicas que cada APL possui, o que leva a resultados diferenciados. Foram entrevistados representantes das seguintes organizações: Centro de Tecnologia em Ação de Desenvolvimento Sustentável (CETEC), o Centro de Tratamento de Resíduos Industriais e o Centro Nacional de Tecnologia da Madeira e do Mobiliário (CETMAM).

No caso específico deste estudo, a análise quantitativa recai na metodologia desenvolvida por Martins e Cândido (2008), a qual foi construída a partir de uma adaptação da metodologia de Waquil e colaboradores (2006), e dos indicadores de desenvolvimento sustentável do IBGE (BRASIL, 2015). A escolha justificou-se tendo em vista que os autores construíram uma metodologia para avaliar os indicadores de sustentabilidade dos municípios, avaliando as seguintes dimensões: social, demográfica, econômica, político-institucional, ambiental e cultural.

\section{Desenvolvimento Sustentável}

A concepção de responsabilidade social empresarial define um novo papel para a empresa dentro da sociedade, que ultrapassa o mercado, afastando-se do conceito exclusivamente econômico. A empresa passa a ser vista como um sistema social organizado que desenvolve ações diversas. Nesta nova concepção a empresa não se orienta apenas por uma lógica de resultados. Ela está deixando de ser uma unidade de produção e tornando-se uma organização, um sistema social, formado por um grupo de pessoas que devem estabelecer e firmar objetivos éticos para orientar suas atividades. Do ponto de vista ambiental, a consciência ecológica empresarial é motivada por pressões contínuas do Poder Público, da opinião pública e dos consumidores, que visam à conservação do ambiente (DIAS, 2009).

Deste modo, as empresas se relacionam com outras do mesmo segmento, assim como com instituições públicas e privadas, além de organizações do terceiro setor, em prol do desenvolvimento de uma cidade e sua região de influência. Uma cidade pode ser definida como uma projeção da sociedade no espaço, a partir de uma estrutura urbana compreendida como o resultado da interação entre a população, o ambiente, a tecnologia e a organização social, cuja análise deve-se reportar à formalização dos processos observados (CASTELLS, 2014). A partir dessa percepção, a sustentabilidade passa a ser vista pelas empresas por uma ótica sistêmica e integradora, a qual é tratada numa perspectiva multidisciplinar, destacando a necessidade da diversidade ambiental, social, cultural e ética, onde deve-se estimular a vida em comunidade, a convivência em espaços públicos abertos, além de participar ativamente das decisões que afetam a vida das pessoas no contexto atual e futuro (HERZOG, 2013).

A partir do estabelecimento das bases para a construção de uma política nacional de Arranjos Produtivos Locais, observou-se que a dimensão territorial tornou-se referência para se pensar um projeto de desenvolvimento para o país. Tal perspectiva convergiu com a preocupação do Governo Federal acerca da problemática da desigualdade regional, a qual passou a constituir uma questão nacional. Neste contexto, o desenvolvimento local assumiu importância estratégica (CASSIOLATO; LASTRES; STALLIVIERI, 2008). A experiência recente tem demonstrado a importância do desenho de políticas que levem em consideração as especificidades de cada território e de sua estrutura produtiva e que mobilize não somente empresas individuais ou segmentos específicos, mas sim o conjunto dos agentes produtivos, organizações de ensino e capacitação, ciência e tecnologia, financiamento, representação e formulação de políticas (BORIN; MATOS; CASSIOLATO, 2014).

O conceito do fenômeno da sustentabilidade, segundo Acselrad (2013), é visto como algo em evolução, sendo que as práticas de sustentabilidade atuais refletirão na sustentabilidade futura. Neste sentido, indicadores de sustentabilidade apresentam-se como instrumentos importantes para a compreensão de uma economia sustentável em determinada região. 


\section{Indicadores De Sustentabilidade}

Um dos desafios da construção do desenvolvimento sustentável é o de criar instrumentos de mensuração, tais como indicadores de desenvolvimento. De acordo com o IBGE (BRASIL, 2015), os indicadores de sustentabilidade são ferramentas constituídas por uma ou mais variáveis que, associadas de diversas formas, revelam significados mais amplos sobre os fenômenos a que se referem. Por sua capacidade de síntese, são capazes de facilitar o entendimento ao crescente público envolvido com o tema, constituindo-se em um instrumento essencial para guiar a ação e subsidiar o acompanhamento do progresso alcançado rumo ao desenvolvimento sustentável. Os indicadores de sustentabilidade diferenciam-se dos demais por exigirem uma visão de mundo integrada, necessitando relacionar, para tanto, a economia, o meio ambiente e a sociedade de uma dada comunidade. Sutil (2004) defende que um bom indicador alerta sobre os problemas antes que se tornem muito graves indicando o que precisa ser feito para resolvê-los. Dessa maneira é que em comunidades em crise os indicadores são considerados importantes instrumentos para definir soluções e propor um futuro promissor.

No caso brasileiro, acresce-se o desafio de propor indicadores capazes de caracterizar e subsidiar o processo de desenvolvimento sustentável em nível municipal, aliada à exigência de expressar as diversidades do país. A partir dessa lacuna na literatura, Martins e Cândido (2008) propuseram um modelo elaborado com base no Índice de Desenvolvimento Sustentável Brasil 2004, elaborado pelo Instituto Brasileiro de Geografia e Estatística - IBGE, o qual permite a avaliação dos níveis de sustentabilidade para o Brasil. A metodologia proposta pelos autores procura identificar o nível de sustentabilidade municipal através de um conjunto de seis dimensões: social, demográfica, econômica, político-institucional, ambiental e cultural. Essas dimensões contêm informações que visam a fornecer subsídios para a formulação e implementação de políticas públicas que propiciem as condições adequadas para a qualidade da vida da população no momento atual e para as futuras gerações. As dimensões e indicadores da metodologia estão abaixo discriminados:

Gráfico 1 - Indicadores que compõem o IDSM

\begin{tabular}{|c|c|}
\hline Dimensões & Indicadores \\
\hline $\begin{array}{l}\text { Político- } \\
\text { Institucional }\end{array}$ & $\begin{array}{l}\text { - Despesas por função: com assistência social, educação, cultura, urbanismo, } \\
\text { habitação urbana, gestão ambiental, ciência e tecnologia, desporto e lazer, } \\
\text { saneamento urbano, saúde; } \\
\text { - Acesso a serviço de telefonia fixa; } \\
\text { - Participação nas eleições; } \\
\text { - Número de conselhos municipais; } \\
\text { - Número de acessos à justiça; } \\
\text { - Transferências intergovernamentais da União. }\end{array}$ \\
\hline Ambiental & $\begin{array}{l}\text { - Qualidade das águas: aferição de cloro residual, de turbidez e de coliformes } \\
\text { totais; } \\
\text { - Tratamento das águas: tratada em ETAs e por desinfecção; } \\
\text { - Consumo médio per capita de água; } \\
\text { - Acesso à coleta de lixo urbano e rural; } \\
\text { - Acesso ao sistema de abastecimento de água; } \\
\text { - Tipo de esgotamento sanitário por domicílio. }\end{array}$ \\
\hline Social & $\begin{array}{l}\text { - Expectativa de vida ao nascer; } \\
\text { - Mortalidade infantil; } \\
\text { - Prevalência da desnutrição total; } \\
\text { - Imunização contra doenças infecciosas infantis; } \\
\text { - Oferta de serviços básicos de saúde; } \\
\text { - Alfabetização; } \\
\text { - Escolaridade; } \\
\text { - Analfabetismo funcional; }\end{array}$ \\
\hline
\end{tabular}




\begin{tabular}{|l|l|}
\hline & - Famílias atendidas com programas sociais; \\
& - Adequação de moradia nos domicílios; \\
& - Mortalidade por homicídio; \\
& - Mortalidade por acidente de transporte. \\
\hline Econômica & - Produto interno bruto (PIB) per capita; \\
& - Participação da indústria no PIB; \\
& - Saldo da balança comercial; \\
& - Renda familiar per capita em salários mínimos; \\
& - Renda per capita; \\
& - Rendimentos provenientes do trabalho; \\
& - Índice de Gini de distribuição do rendimento. \\
\hline Demográfica & - Crescimento da população; \\
- Razão entre a população urbana e rural; \\
- Densidade demográfica; \\
- Razão entre a população masculina e feminina; \\
- Distribuição da população por faixa etária. \\
\hline - Quantidade de bibliotecas; \\
- Quantidade de museus; \\
- Quantidade de ginásios de esportes e estádios; \\
- Quantidade de cinemas; \\
- Quantidade de unidades de ensino superior; \\
- Quantidade de teatros ou salas de espetáculos e \\
- Quantidade de centros culturais.
\end{tabular}

Fonte: Martins \& Cândido (2008).

Como pode ser observado no quadro, muitas são as variáveis necessárias apresentadas por Martins e Cândido (2008) para se identificar o nível de sustentabilidade municipal. Entretanto, sabe-se da necessidade de se levar em consideração as especificidades do município que se está analisando, bem como destacar o nível de importância que cada dimensão e variável representa, principalmente, como elementos indispensáveis para conduzir políticas e ações desenvolvimentistas. Nesse sentido, a forma como se deve quantificar a importância relativa de cada dimensão e variável torna-se preponderante em função de que possuem importâncias variáveis para cada município. Dessa forma, suas escolhas devem estar atreladas à utilização de critérios adequados, os quais podem ser estabelecidos por meio de sistemas de apoio à decisão.

Para Martins e Cândido (2009), o processo de tomada de decisão se desenvolve na interação constante do tomador de decisão com o ambiente para o qual as decisões serão direcionadas, as quais envolvem uma série de consequências e riscos. Assim, torna-se importante identificar as prioridades com uma visão a longo prazo, principalmente, quando se tem divergências de recursos e informações. A análise da informação não deve se atrelar somente aos Índices de Sustentabilidade.

\section{Considerações Sobre O Método}

Conforme Minayo (2010), uma pesquisa, por ser quantitativa, não se torna objetiva e melhor, ainda que se prenda à manipulação sofisticada de instrumentos de análise. Esta característica matemática, caso deforme ou desconheça aspectos importantes dos fenômenos ou processos sociais estudados, não fornecerá uma boa análise. Uma abordagem qualitativa juntamente com a quantitativa garante uma compreensão em profundidade.

$\mathrm{O}$ paradigma fenomenológico se interessa em entender o comportamento humano, tendo como referência o participante. Segundo Collis e Hussey (2005), é uma proposta qualitativa que enfatiza aspectos subjetivos focando o significado e não a mensuração de fenômenos sociais. Examinando pequenas amostras, durante certo período de tempo, usando métodos diferentes de pesquisa para obter percepções diferenciadas, sua análise tenta entender o que está acontecendo em uma situação e procurará estabelecer padrões que poderão repetir-se em 
outras situações.

Como meio de investigação, o Estudo de Caso é um método que, segundo Yin (2015), é utilizado para estudos que visam a descobrir a causa e forma pela qual ocorrem os fenômenos. O Estudo de Caso pode ser complementado por outros meios de investigação, como, por exemplo, Estudos Longitudinais propostos por Collis e Hussey (2005), buscando investigar a dinâmica do problema, observando repetidamente com objetivo de revelar a estabilidade relativa dos fenômenos. Isso permite que se examine o processo de mudança dentro de um contexto social, econômico e político. Um Estudo Longitudinal baseia-se em dados qualitativos que formam uma cadeia de estudos, característica que aperfeiçoa a aplicabilidade e a validade das descobertas.

A coleta de dados na primeira fase do trabalho diz respeito à fundamentação metodológica e teórica. Essas informações foram extraídas de fontes secundárias como institutos de pesquisa, assim como fontes bibliográficas e documentos eletrônicos. Já na segunda fase, foram realizadas entrevistas com questões abertas com o intuito de buscar dados mais específicos. Vale ressaltar que essas informações de embasamento serviram para a formulação de hipóteses (MINAYO, 2010).

$\mathrm{Na}$ análise e interpretação dos dados foi utilizado o protocolo de Estudo de Caso proposto por Yin (2015), cuja função foi aumentar a confiabilidade da pesquisa. O autor apresenta de forma concisa os dados teóricos que sustentam o estudo. A pesquisa se subdivide em proposições de referencial teórico e de descrição de caso. As suposições modelaram o plano de coleta de dados dando prioridade à estratégia geral, fornecendo orientação teórica que direciona a análise do estudo, ajudando a focalizar a atenção sobre determinados dados e ignorando outros, além de auxiliar na organização como um todo, definindo explicações alternativas examinadas.

\section{Procedimentos Metodológicos}

Para dar suporte à investigação, optou-se por trabalhar com a análise quantitativa, feita por meio dos indicadores de sustentabilidade propostos por Martins e Cândido (2008). Utilizou-se também análise qualitativa por meio de estudo de caso juntamente com Estudos Longitudinais propostos por Collis e Hussey (2005). A análise quantitativa deve ser utilizada para abarcar, do ponto de vista social, grandes aglomerados de dados classificando-os e tornando-os inteligíveis por meio de variáveis. A análise qualitativa adequa-se a aprofundar a complexidade de fenômenos, fatos e processos particulares e específicos de grupos mais ou menos delimitados em extensão e capazes de serem abrangidos intensamente (MINAYO, 2010).

A pesquisa pode ser considerada exploratória e descritiva, busca testar e aplicar uma nova metodologia, bem como compreender fenômenos sociais. Já com relação à sua natureza, pode ser classificada como pesquisa aplicada, dada a sua intenção de propor um instrumento de otimização de metodologias já construídas, incorporando às mesmas um novo componente teórico e técnico.

A seleção dos indicadores para esta pesquisa não precisou partir do marco zero, uma vez que utilizou iniciativas já existentes e utilizadas com sucesso. Para a definição do conjunto de indicadores, tomou-se como referência o modelo de "Indicadores de Desenvolvimento Sustentável dos Estados Brasileiros e dos Municípios da Paraíba", proposto por Martins e Cândido (2008), do qual foram extraídos cinquenta e um indicadores que foram organizados em quatro dimensões e treze temas. Mas, por se tratar de uma outra região, os dados foram adaptados. Como fonte direta de pesquisa utilizaram-se dados do Instituto Paranaense de Desenvolvimento Econômico e Social (IAPARDES, 2016) e do Instituto Brasileiro de Geografia e Estatística (BRASIL, 2015), Ministério Público do Paraná (PARANÁ, 2016b), Prefeitura do Município de Arapongas (PARANÁ, 2016c) e Companhia de Saneamento do Paraná (PARANÁ, 2016a).

O "Indicador de Desenvolvimento Sustentável do Município" (IDSM) seria o resultado da agregação de quatro índices temáticos, a saber: Índice Ambiental (IA), Índice Econômico (IE), Índice Social (IS) e Índice Institucional (II), no processo inicial de seleção dos indicadores para o IDSM. Para uniformização dos indicadores, recomenda-se uma padronização utilizando o método de transformação de todas as variáveis para valores situados entre 0 (pior situação observada) e 1 (melhor situação observada). Este procedimento evita os efeitos de unificação das variâncias e de geração de escores negativos. Para uma variável $\boldsymbol{x}$ qualquer, o valor da variável transformada 0-1 para a i-ésima observação pode ser obtido pelas expressões 1 ou 2 , considerando-se a relação positiva ou negativa de cada variável.

- Relação positiva:

$$
\begin{gathered}
\boldsymbol{I}=(\boldsymbol{X}-\boldsymbol{m}) /(\boldsymbol{M}-\boldsymbol{m})(1) \\
\bullet \quad \text { Relação negativa: } \\
\boldsymbol{I}=(\boldsymbol{m}-\boldsymbol{X}) /(\boldsymbol{M}-\boldsymbol{m})(2)
\end{gathered}
$$


onde:

I - índice calculado para o municipio analisado;

$x$ - valor de cada variável para o município;

m - valor mínimo da variável identificado nessa localidade;

$M$ - valor máximo da variável identificado nessa localidade.

Matematicamente o IDSM foi calculado pela agregação ponderada aditiva dos seus quatro índices temáticos, conforme a expressão 4:

$\mathrm{IDSM}=[\mathrm{Pe}($ Ieconômico $)+\mathrm{Ps}($ Isocial $)+\mathrm{Pa}($ Iambiental $)+\mathrm{Pi}($ Iinstitucional $)] / \mathrm{Pe}+\mathrm{Ps}+\mathrm{Pa}+\mathrm{Pi}(4)$

onde:

IDSM - indice de desenvolvimento sustentável municipal

IA - indice ambiental

IE - índice econômico

IS - índice social

II - indice institucional

Pn - pesos de cada índice ( $\Sigma p n=1)$

Os dados relativos a esse índice foram inseridos em uma escala, permitindo a classificação dos mesmos em faixas sinalizadas de acordo com o "semáforo da sustentabilidade". Quanto maior o IDSM, ou valor mais próximo de 1, maior o nível de sustentabilidade do local.

Em complemento às informações fornecidas pelo IDSM, optou-se por um estudo de caso, em que foram entrevistados representantes das seguintes organizações: Centro de Tecnologia em Ação de Desenvolvimento Sustentável (CETEC), o Centro de Tratamento de Resíduos Industriais e o Centro Nacional de Tecnologia da Madeira e do Mobiliário (CETMAM). Essas instituições e as empresas, juntamente com as indústrias do Polo Moveleiro de Arapongas deram início à implantação de um Arranjo Produtivo Local. Foi importante fazer esse tipo de análise para compreender o contexto em que se inserem e qual a real possibilidade da continuação do APL. Não se consegue por meio dos índices compreender o objetivo a longo prazo do Polo; eles podem confirmar se o APL está atingindo seus objetivos ou não. $\mathrm{Na}$ análise, foram apresentadas as visões de organizações que se complementam nesse ecossistema de negócios.

A coleta de dados na primeira fase foi feita por meio de informações extraídas de fontes secundárias como fontes bibliográficas e documentos eletrônicos. Já na segunda fase foram realizadas pesquisas diretas por meio de entrevistas com questões abertas com o intuito de buscar dados mais específicos. Para não desvirtuar a coleta de dados na segunda parte da pesquisa se utilizou o protocolo de Estudo de Caso proposto por Yin (2015). Os dados foram coletados em um ambiente não controlado, onde o pesquisador teve que se adaptar à realidade dos entrevistados. O ponto principal do protocolo consiste em um conjunto de questões que foram formuladas por meio de fontes de evidências. Estas, por sua vez, constituem-se em documentos, registros em arquivos, observação direta, observação participante, além de artefatos físicos.

\section{Resultados e Discussão}

Segundo a empresa pesquisada, o Sindicato das Indústrias de Móveis de Arapongas (SIMA), o Polo moveleiro do interior do Paraná é formado por novecentos e setenta e nove indústrias, sendo cento e setenta e dois em uma cidade e as demais distribuídas em treze municípios. Essas empresas são responsáveis por aproximadamente dezenove mil e novecentos e setenta empregos diretos e três mil e cinquenta e cinco indiretos. A região fabrica $10 \%$ dos móveis produzidos no Brasil, é a segunda do país em produção e vendas, sendo responsável por 9,97\% do Produto Interno Bruto (PIB) nacional. Esse setor é responsável por 67,43\% da cidade de Arapongas. Cerca de $90 \%$ da produção do parque industrial é comercializada no país, os outros $10 \%$ são exportados. As exportações, por sua vez, subdividem-se: 33\% para os Estados Unidos, 9\% para França, 9\% para o Reino Unido, 8\% para Argentina, 4\% para Espanha e 37\% para outros países.

Esse ambiente proporcionou a criação de Arranjos Produtivos Locais de Móveis na região. O SIMA define Arranjos Produtivos Locais (APL) como um conjunto de empresas de um mesmo setor localizadas numa mesma região ou município visando à promoção da competitividade e beneficiamento de seus integrantes, além do desenvolvimento econômico, social e tecnológico, engajando comunidades locais, centro de tecnologia e pesquisa. No setor moveleiro, existem apenas três municípios que possuem projetos como o descrito. No Paraná, 
o foco estratégico é a internacionalização: ela é vista como forma de alavancar mercados e a gestão das indústrias, tanto do ponto de vista empresarial quanto produtivo.

Além do aumento das exportações, o Arranjo Produtivo Local objetiva envolver todos os segmentos da cadeia produtiva, fortalecendo o setor e otimizando resultados, gerando mais empregos e produção. Outras metas perseguidas são os investimentos em profissionalização de mão de obra e design. Existem programas de qualificação que garantem às indústrias da região alta qualidade tanto em sua produção quanto em suas estratégias administrativas. O Centro Nacional de Tecnologia da Madeira e do Mobiliário (CETMAM), que é mantido pelo Serviço Nacional de Aprendizagem Industrial do Paraná (SENAI-PR), presta serviços de assessoria técnica e tecnológica disponibilizando laboratórios de pesquisa em produtos do mobiliário, cursos e treinamentos, sendo conhecido como "Universidade da Mobília". Embora não seja um curso superior, conta com instrutores focados no setor moveleiro que recebem capacitação tanto no Brasil quanto no exterior. Sobre capacitação fora do país, há um acordo de cooperação técnica entre o SENAI-PR e o Ministério da Economia de Baden-Württemberg, na Alemanha.

Neste contexto, o Centro de Tecnologia em Ação de Desenvolvimento Sustentável (CETEC), o qual pode-se dizer que é uma OSCIP, criada em dezembro de 2000, com o objetivo de promover o desenvolvimento sustentável executando programas e serviços na área ambiental, envolve toda a cadeia produtiva do Polo Moveleiro de Arapongas. Surgiu da parceria entre o SIMA e as empresas da região, as quais precisavam destinar corretamente seus resíduos para não serem autuadas por órgãos de fiscalização ambiental. Foram feitas doações para a fundação do CETEC, o qual criou a parte operacional de destinação dos resíduos terceirizada pela usina de reciclagem (SIMA, 2016).

A missão do CETEC/OSCIP é apoiar e executar programas, projetos e serviços nas áreas: ambiental, social e cultural. Visa a promover o desenvolvimento sustentável oferecendo prestação de assistência técnica, assessorias, consultorias, certificação de florestas e de produtos da cadeia de custódia, organização de eventos e empreendimentos; fundamentais para o desenvolvimento e modernização da sociedade. A OSCIP busca transformar resíduos decorrentes do processo produtivo em materiais recicláveis para encontrar melhores opções ambientais, sociais e econômicas para a autossustentabilidade do setor moveleiro. Sua principal preocupação é encontrar alternativas que agreguem valores aos produtos produzidos, além de preservar o meio ambiente. A OSCIP visa ao desenvolvimento contínuo e eficiente por meio de seminários, treinamentos, educação ambiental e ações realizadas no interior das indústrias participantes do programa. Como resultado dessa abordagem de reutilização interna de resíduos industriais ocorre um ganho na produção industrial e uma economia real no processo produtivo. A recuperação e segregação dos resíduos possibilita novos produtos, diminuindo o descarte em aterros industrias, evitando a contaminação do solo, sendo a meta da organização reprocessar $100 \%$ dos resíduos gerados (SIMA, 2016).

Em 2001, foi inaugurada a Central de Tratamento de Resíduos Industriais, a qual se constitui em uma usina de reciclagem de resíduos do Polo Moveleiro de Arapongas, terceirizada pelo CETEC/OSCIP. Há um contrato entre as duas organizações, onde a OSCIP encaminha as sobras do processo produtivo para serem beneficiadas e comercializadas. Segundo entrevistado da empresa, a razão social da CETEC é Pontalti - Indústria e Comércio de Resíduos de Madeira Ltda., possuindo duas importantes marcas para produtos reciclados: Termovinil, referente às tintas e solventes, e Briquepar, relacionada à produção de briquetes fabricados a partir de pó de serra, restos e retalhos de madeira. A empresa possui duas unidades da Briquepar, uma em Arapongas e outra em Telêmaco Borba fundada em 2005, ambas no Estado do Paraná.

A unidade de Arapongas recebe duzentas e cinquenta toneladas de resíduos por dia, dos quais $90 \%$ referem-se a resíduos de madeira como serragem e pó. Sua capacidade produtiva é de trezentas e cinquenta toneladas diárias; além disso, possui aproximadamente oito mil toneladas de matéria-prima para atender seus clientes emergencialmente. Emprega diretamente cento e trinta funcionários em todo o processo, o qual é caracterizado por ser extremamente manual. O briquete produzido, devido a suas características, é recomendado para alimentação de caldeiras a vapor. Já o briquete produzido pela unidade de Telêmaco, derivado de serragem de Eucalyptus, é recomendado para fornos como de pizzarias e padarias. O briquete é comercializado em todo o Estado do Paraná e parte do Estado de São Paulo. As empresas atendidas possuem diferentes perfis que variam desde fábrica de rações a pizzarias na capital paulista.

Ao se analisar todo o contexto socioeconômico, as influências regionais e como estão organizadas as empresas e as organizações, conclui-se que as indústrias moveleiras de Arapongas, a princípio, buscaram junto à prefeitura, ao SIMA e ao SEBRAE a formação de um APL para compartilhar responsabilidades, objetivando criar infraestrutura para exportações. É uma rede de empreendimentos, formada por integrantes do setor privado, 
público e da sociedade civil, localizados numa mesma região, interligando-se e agregando diversas competências, tendo como foco principal o atendimento de necessidades maiores (IOSCHPE, 2015). As necessidades estão relacionadas ao desenvolvimento sustentável; no caso de Arapongas, seria desenvolver parcerias que destinassem os resíduos das indústrias moveleiras de maneira correta.

O CETEC/OSCIP faz a ponte entre as empresas, aplicando princípios de administração na gestão social em que exerce para não perder o foco e coordenar melhor a rede de cooperação da qual faz parte. Conforme Villas-Boas (2003), percebe-se na entidade: orientação por valores, manutenção e legitimidade do projeto, e associação com o Estado e empresas privadas. Sua criação só foi possível em função da parceria da prefeitura com as indústrias de Arapongas. Atualmente a OSCIP possui autonomia administrativa, porém constrói uma rede de interdependência com estas esferas.

Após as entrevistas, foi feito o levantamento de dados para o cálculo do IDSM. Para montar a tabela com dimensões e indicadores da metodologia proposta, utilizaram-se dados provenientes do Instituto Paranaense de Desenvolvimento Econômico e Social (IPARDES) e do Instituto Brasileiro de Geografia e Estatística (IBGE), Ministério Público do Paraná, Prefeitura do Município de Arapongas e Companhia de Saneamento do Paraná (SANEPAR). Além de Martins e Cândido (2008), para o cálculo dos índices trabalhou-se com Souza e colaboradores (2012) e Vasconcelos (2011), os quais esclareceram o processo de formação de alguns índices.

Foram observadas as mesmas dificuldades que Souza e colaboradores (2012) tiveram ao elaborar os índices. Fez-se necessário realizar uma imputação de valores para os indicadores que não possuíam informação, para que não houvesse distorções no cálculo do Indicador Social de Desenvolvimento dos Municípios (ISDM). As informações extraídas nem sempre estão disponíveis para a totalidade dos municípios, por exemplo: quando não há informação sobre a distribuição da população por faixa etária. A população da cidade de Arapongas é de 116.960 habitantes, sendo atendidos conforme dados da tabela a seguir:

Gráfico 2 - Indicadores que compõem o IDSM de Arapongas-PR

\begin{tabular}{|c|c|c|}
\hline Dimensões & Indicadores & Dados \\
\hline $\begin{array}{l}\text { Político- } \\
\text { Institucional }\end{array}$ & $\begin{array}{l}\text { - Despesas por função: com assistência social, educação, cultura, } \\
\text { urbanismo, habitação urbana, gestão ambiental, ciência e tecnologia, } \\
\text { desporto e lazer, saneamento urbano, saúde (em reais); } \\
\text { - Acesso a serviço de telefonia fixa (habitantes); } \\
\text { - Participação nas eleições (habitantes); } \\
\text { - Número de conselhos municipais (unidades); } \\
\text { - Número de acessos à justiça (unidade); } \\
\text { - Transferências intergovernamentais da União (reais). }\end{array}$ & $\begin{array}{r}205.922 .907,31 \\
17.426 \\
82.043 \\
13 \\
1 \\
167.488 .359,29\end{array}$ \\
\hline Ambiental & $\begin{array}{l}\text { - Qualidade das águas: aferição de cloro residual, de turbidez e de } \\
\text { coliformes totais (\%); } \\
\text { - Tratamento das águas: tratada em ETAs e por desinfecção; } \\
\text { - Consumo médio per capita de água (\%); } \\
\text { - Acesso à coleta de lixo urbano e rural (habitantes); } \\
\text { - Acesso ao sistema de abastecimento de água (habitantes); } \\
\text { - Tipo de esgotamento sanitário por domicílio. }\end{array}$ & $\begin{array}{r}1,20 \\
- \\
41 \\
32.349 \\
40.708\end{array}$ \\
\hline Social & $\begin{array}{l}\text { - Esperança de vida ao nascer (índice); } \\
\text { - Mortalidade infantil (\% a cada } 1.000 \text { habitantes); }\end{array}$ & $\begin{array}{r}0.84 \\
15,97\end{array}$ \\
\hline
\end{tabular}




\begin{tabular}{|c|c|c|}
\hline & $\begin{array}{l}\text { - Prevalência da desnutrição total (\%); } \\
\text { - Imunização contra doença infecciosa infantil (\%); } \\
\text { - Oferta de serviços básicos de saúde (unidades); } \\
\text { - Escolarização (habitantes); } \\
\text { - Alfabetização (\%); } \\
\text { - Escolaridade (índice); } \\
\text { - Analfabetismo funcional (\%); } \\
\text { - Famílias atendidas com programas sociais (habitantes); } \\
\text { - Adequação de moradia nos domicílios (habitantes); } \\
\text { - Mortalidade por homicídio (\%); } \\
\text { - Mortalidade por acidente de transporte (\%). }\end{array}$ & $\begin{array}{r}15 \\
99 \\
230 \\
22.438 \\
74,81 \\
0,56 \\
25,19 \\
16.829 \\
36.144 \\
6,93 \\
8\end{array}$ \\
\hline Econômica & $\begin{array}{l}\text { - Produto interno bruto (PIB) per capita (reais); } \\
\text { - Participação da indústria no PIB (\%); } \\
\text { - Saldo da balança comercial (Reais); } \\
\text { - Renda Familiar per capita em salários mínimos (reais); } \\
\text { - Renda per capita (índice); } \\
\text { - Rendimentos provenientes do trabalho (\%); } \\
\text { - Índice de Gini de distribuição do rendimento (índice). }\end{array}$ & $\begin{array}{r}37.457 \\
9,97 \\
-81.769 .028 \\
\\
835,11 \\
0,84 \\
95,99 \\
0,47\end{array}$ \\
\hline Demográfica & $\begin{array}{l}\text { - Crescimento da população (índice); } \\
\text { - Razão entre a população urbana e rural (\%); } \\
\text { - Densidade demográfica (habitante por km²); } \\
\text { - Razão entre a população masculina e feminina (\%); } \\
\text { - Distribuição da população por faixa etária. }\end{array}$ & $\begin{array}{r}2 \\
97,79 \\
306,49 \\
96,09\end{array}$ \\
\hline Cultural & $\begin{array}{l}\text { - Quantidade de bibliotecas; } \\
\text { - Quantidade de museus; } \\
\text { - Quantidade de ginásios de esportes e estádios; } \\
\text { - Quantidade de cinemas; } \\
\text { - Quantidade de unidades de ensino superior; } \\
\text { - Quantidade de teatros ou salas de espetáculos; } \\
\text { - Quantidade de centros cultural. }\end{array}$ & $\begin{array}{l}2 \\
2 \\
3 \\
1 \\
2 \\
2 \\
1\end{array}$ \\
\hline
\end{tabular}

Fonte: Elaborado a partir de Martins e Cândido (2008).

O ISDM é construído de maneira a indicar quanto maior o seu valor, maior o nível de desenvolvimento do município. Ele é obtido como uma média simples dos indicadores de cada dimensão, que são estabelecidos numa escala de 0 a 1. Para que haja consistência na comparação entre todos os municípios do país, os indicadores agregados das dimensões e o ISDM são normalizados de forma que cada um deles represente o desvio em relação à média do Brasil. Para o cálculo do ISDM, o primeiro passo é ajustar cada um dos indicadores para que ele varie numa escala de 0 a 1 , sendo que, quanto mais perto de 1 , mais bem avaliado estará o município e, quanto mais perto de zero, pior será sua avaliação neste indicador (SOUZA et al, 2012).

Para representação dos índices referentes a cada variável, os IDSMs das dimensões e os IDSMs finais foi 
utilizado um conjunto de cores que correspondem aos níveis de sustentabilidade explicitados para cada localidade. O quadro a seguir mostra a classificação e representação dos índices (variação de 0 a 1) pela cor correspondente conforme escala definida por Martins e Cândido (2008):

Gráfico 3 - Classificação do IDSM conforme performance

\begin{tabular}{|c|c|c|}
\hline Índice (0 - 1) & Coloração & Performance \\
\hline $0,7501-1,0000$ & & Ideal \\
\hline $0,5001-0,7500$ & & Aceitável \\
\hline $0,2501-0,5000$ & & Alerta \\
\hline $0,0000-0,2500$ & & Crítica \\
\hline
\end{tabular}

Fonte: Martins e Cândido (2008)

Após cálculo do IDSM de Arapongas, chegou-se aos seguintes índices e classificação:

Gráfico 4 - Classificação das dimensões do IDSM de Arapongas-PR

\begin{tabular}{|c|c|c|c|}
\hline Dimensão & Índice (0 - 1) & Coloração & Performance \\
\hline Social & 0,9237 & & Ideal \\
\hline Demográfica & 0,5536 & & Aceitável \\
\hline Econômica & 0,7171 & & Aceitável \\
\hline Político-Institucional & 0,7904 & & Aceitável \\
\hline Ambiental & 0,4507 & & Alerta \\
\hline Cultural & 1 & & Ideal \\
\hline & & & Aceitável \\
\hline IDSM ARAPONGAS & 0,7392 & & \\
\hline
\end{tabular}

Fonte: Elaborado a partir de Martins e Cândido (2008)

Analisando-se os dados, verificou-se que o IDSM do APL de Arapongas é considerado aceitável - o índice é de 0,7392 . No que diz respeito às dimensões cultural e social, o município demonstra que vem investindo maciçamente em saúde, educação, cultura e lazer. Estes resultados vão ao encontro das expectativas do Arranjo Produtivo, o qual vem concentrando esforços na profissionalização da mão de obra. $\mathrm{O}$ acesso da população aos programas de educação e saúde de qualidade assegura sua permanência na cidade e por consequência acabam por movimentar a economia da região. Sobre o aspecto econômico, o desempenho do APL é aceitável. A distribuição de renda é igualitária e cerca de $95 \%$ da população economicamente ativa possui renda proveniente do setor moveleiro, logo, a manutenção deste setor demonstra-se importante. Do ponto de vista políticoinstitucional, verificou-se que os dirigentes acertaram em várias questões, mas devido à falta de maior atenção às questões ambientais o APL não atingiu a classificação ideal.

A questão ambiental impede a aquisição de certificação e por consequência desenvolvimento do APL de Arapongas. Isso ocorre por falta de investimentos em saneamento básico, tratamento das águas e deficiência na distribuição de água tratada à população. Por parte das indústrias, mesmo com a atuação do CETEC/OSCIP, os resíduos ainda não são destinados da forma mais adequada. Segundo Prates, Lopes e Bolonhesi (2016), os resíduos líquidos das indústrias moveleiras são classificados como resíduos Classe I - perigosos, devido às características de periculosidade apresentada por seus componentes constituintes. O percentual dos volumes de resíduos gerados na lavagem de maquinário é constantemente lançado na rede coletora de esgoto sanitário. Esses efluentes apresentam em sua composição, além do solvente, restos de cola, cujo um dos componentes principais é o formaldeído, classificado como carcinogênico para humanos.

O Polo Moveleiro de Arapongas tem grande potencial de perpetuação e de se desenvolver de maneira sustentável. O fato de ter uma classificação aceitável pelo IDSM bem próximo ao nível ideal retrata essa realidade. A região possui instituições que estão no caminho devido lançando esforços na questão ambiental. Já existem legislação ambiental e medidas para recuperação de matérias-primas e energia, como, também, 
reaproveitamento de resíduos na geração de aglomerados de madeira.

$\mathrm{Na}$ realidade, para pequena e média indústria moveleira há necessidade iminente da revisão dos processos produtivos, buscando inserção da variável ambiental, com sistemas de gerenciamento e licenciamento ambiental compatíveis com a legislação vigentes (PRATES; LOPES; BOLONHESI, 2016). O orçamento anual para tratamento de efluentes e da qualidade das águas, assim como sua distribuição deve receber uma atenção especial por parte dos poderes executivo e legislativo. Vale ressaltar que o bom desempenho educacional, futuramente, contribuirá para a melhoria desse índice.

\section{Considerações Finais}

A manutenção e durabilidade de um APL dependem de como são levadas em consideração as dimensões: social, econômica, demográfica, cultural, político-institucional e ambiental. A vocação econômica da região é importante, como também é preciso desenvolver parcerias público-privadas que beneficiem o conglomerado industrial, propiciando à população atendimento de suas necessidades básicas, um equilíbrio proporcionado por leis regulamentadoras, educação e ética em cumprir medidas pré-estabelecidas para o alcance de resultados almejados. Descuidos nestes aspectos fundamentais podem inviabilizar o Arranjo Produtivo a longo prazo.

A contribuição deste trabalho pesa na reflexão sobre responsabilidade socioeconômica e socioambiental que se deve ter na implantação de um APL, bem como na importância de se mensurar índices para facilitar a tomada de decisões dentro deste conglomerado.

Os temas merecem continuar sendo tratados com a devida seriedade, observando que a tendência é de que sustentabilidade não está somente relacionada a desempenho financeiro, mas a um conjunto de fatores relacionados ao Estado, às empresas privadas e às organizações do terceiro setor. $\mathrm{O}$ estudo dos índices podem demonstrar os setores que precisam ser melhorados, possibilitando uma análise em tempo real que complemente os fenômenos estudados. Ao somar investimentos, trabalho e pesquisa alcança-se o desenvolvimento de uma região, além de trazer benefícios aos participantes do projeto.

A expressão "APL sustentável” abarca desde uma administração pública de qualidade garantindo saúde, educação e saneamento básico, até a aquisição de certificação de excelência na produção industrial para alcançar novos mercados. Para se atingir os patamares mais elevados economicamente, os problemas de infraestrutura de uma região devem ter mais atenção. Isso não depende unicamente dos governos, mas das organizações privadas, além da contribuição da própria população.

\section{Referências}

ACSELRAD, H. Cidade - espaço público? A economia política do consumismo nas e das cidades. Revista da Universidade Federal de Minas Gerais, Belo Horizonte (Online), v. 20, p. 235-247, 2013. Disponível em: $<$ https://www.ufmg.br/ revistaufmg/downloads/20/11-cidadeespaco_p_blico_henri_aselrad.pdf $>$. Acesso em: 09 dez. 2016.

BORIN, E. C. P.; MATOS, M. P.; CASSIOLATO, J. E. Arranjos Produtivos Locais Brasileiros ao longo de uma década: sua evolução e o papel das políticas públicas. Espacios, Caracas, v. 35, p. 6-17, 2014. Disponível em: $<$ http://www.revistaespacios.com/a14v35n09/14350907.html>. Acesso em: 26 nov. 2016.

BRASIL. Indicadores de desenvolvimento sustentável: IBGE. Rio de Janeiro, 2015. Disponivel em: $<$ http://biblioteca.ibge.gov.br/visualizacao/livros/liv94254.pdf>. Acesso em: 24 out. 2016.

CASSIOLATO, J. E.; LASTRES, H. M. M.; STALLIVIERI, F. Estratégias para o desenvolvimento: um enfoque sobre arranjos produtivos locais do Norte, Nordeste e Centro-Oeste. Rio de Janeiro: E-Papers, 2008.

CASTELLS, M. A questão urbana. 6. ed. São Paulo: Paz e Terra, 2014.

COLLIS, J.; HUSSEY, R. Pesquisa em administração: um guia prático para alunos de graduação e pósgraduação. 2. ed. Porto Alegre: Bookman, 2005.

DIAS, R. Gestão ambiental: responsabilidade social e sustentabilidade. São Paulo: Atlas, 2009.

HERZOG, C. P. Cidade para todos: (re)aprendendo a conviver com a natureza. Rio de Janeiro: Mauad $\mathrm{X} /$ Inverde, 2013.

IAPARDES. Caderno estatístico do município de Arapongas. Curitiba, 2016. Disponível em: $<$ http://www.ipardes.gov.br/cadernos/MontaCadPdf1.php?Municipio= 
86700\&btOk=ok $>$. Acesso em: $18 \mathrm{dez} 2016$.

IOSCHPE, E. B. (Org.). $3^{\circ}$ Setor: desenvolvimento social sustentado. 3. ed. São Paulo: Paz e Terra, 2015.

MARTINS, F. M. A Influência dos índices de desenvolvimento sustentável na competitividade sistêmica: um estudo exploratório no arranjo produtivo local de confecções em Campina Grande-PB. Dissertação de Mestrado (Programa de pós-graduação em engenharia de produção), Universidade Federal da Paraíba, João Pessoa, 2008. Disponível em: <http://revistas.una.br/index. php/reuna/article/view/432>. Acesso em: 10 nov. 2016.

MARTINS, F. M.; CÂNDIDO, G. A. Índice de desenvolvimento sustentável para municípios (IDSM): metodologia para análise e cálculo do IDSM e classificação dos níveis de sustentabilidade - uma aplicação no Estado da Paraíba. João Pessoa: Sebrae, 2008. Disponível em: < http://pbsrvlamp.sebraepb.com.br/metodologia IDSM.pdf >. Acesso em: 10 nov. 2016.

MARTINS, F. M.; CÂNDIDO, G. A.; SILVA, M. G. Método de construção do índice de desenvolvimento local sustentável: uma proposta metodológica e aplicada. Revista Brasileira de Produtos Agroindustriais, Campina Grande, v.11, n.1, p.55-72, 2009. Disponível em: <http://www.deag.ufcg.edu.br

/rbpa/rev111/Art1118.pdf $>$. Acesso em: 10 nov. 2016.

MINAYO, M. C. S. (Org.). Pesquisa social: teoria, método e criatividade. 29. ed. Petrópolis: Vozes, 2010.

PARANÁ. Companhia de Saneamento do Paraná (SANEPAR). Análise da qualidade da água. 2016a. Disponível em: <http://site.sanepar.com.br/conteudo/analise-da-qualidade-da-agua. Acesso em 19 dez. 2016.

PARANÁ. Ministério Público. Informações municipais para o planejamento institucional. Curitiba, $2016 \mathrm{~b}$. Disponível em: <http://www2.mppr.mp.br/cid/arapongas.pdf>. Acesso em: 19 dez. 2016.

PARANÁ. Prefeitura do Município de Arapongas. Conselhos Municipais. Arapongas, 2016c. Disponível em: $<$ http://www.arapongas.pr.gov.br/utilidades\#conselhos_municipais>. Acesso em: 19 dez. 2016.

PRATES, Kátia Valéria Marques Cardoso; LOPES, Deize Dias; BOLONHESI, Isabela Bruna Tavares de Machado. Diagnóstico ambiental e gerenciamento de resíduos na indústria moveleira. 2016. Anais do VI Congresso Brasileiro de Engenharia de Produção, Ponta Grossa, 2016. Disponível em: $<$ http://aprepro.org.br/conbrepro/2016/anais

2016.php?ordem01=titulo\&ordem02=titulo>. Acesso em: $23 \mathrm{dez} .2016$.

SIMA. Sindicato das Indústrias de Móveis de Arapongas. Programas e projetos. Disponível em: $<$ http://www.sima.org.br>. Acesso em: 06 nov. 2016.

SOUZA, André Portela et al. Indicador social de desenvolvimento dos municípios - ISDM. Nota técnica (Centro de microeconomia aplicada), Fundação Getúlio Vargas, São Paulo, 2012. Disponível em: $<$ http://cmicro.fgv.br/sites/cmicro.fgv.br/files/file/Nota\%20T\%C3\%A9cnica(1).pdf>. Acesso em: 15 dez. 2016.

SUTIL, Arilde Camargo ; UGAYA, Cassia Maria Lie ; PERALTA, Libia Patricia Agudelo. Proposta de definição de indicadores de sustentabilidade para a geração de energia elétrica. Revista Educação \& Tecnologia, Curitiba, v. $8, \quad$ n.1, p. 1-21, 2004. Disponível em: <http://www.utfpr.edu.br/curitiba/estruturauniversitaria/diretorias/dirppg/grupos/tema/

49proposta_energia_eletrica.pdf>. Acesso em: 15 dez. 2016.

VASCONCELOS, A. C. F.. Índice de desenvolvimento sustentável municipal participativo: uma aplicação no município de Cabaceiras- PB. Dissertação de pós-graduação (Programa de pós-graduação em engenharia de produção), Universidade Federal da Paraíba, João Pessoa, 2011. Disponível em: < http://tede.biblioteca.ufpb.br/

bitstream/tede/5289/1/arquivototal.pdf>. Acesso em: 16 dez. 2016.

VILLAS-BOAS NETO, A.; STEFANI, M.; PEZZI JUNIOR, S, Gestão de marketing para organizações do terceiro setor: público - privado - terceiro setor. Londrina: Midiograf, 2003.

WAQUIL, P. D. et al. Avaliação de Desenvolvimento Territorial em Quatro Territórios Rurais no Brasil. Porto Alegre: UFRGS, 2006. Disponível em: <http://www8.ufrgs.br/ppge/pcientifica/2007_04.pdf >. Acesso em: 10 dez. 2016. 
WBCSD. World business council for sustainable development. Eco- Efficiency and Cleaner Production: Charting the Course to Sustainability. UNEP-Environment Programme, 2011. Disponível em: $<$ http://teclim.ufba.br/jsf/ecoeficiencia/ecoef\%20\%20cp\%20unep.html.pdf>. Acesso em: 10 dez. 2016.

YIN, R. K. Estudo de caso: planejamento e métodos. 5. ed. Porto Alegre: Bookman, 2015. 